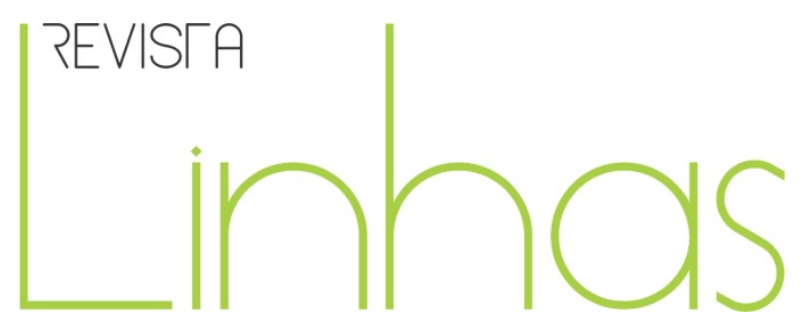

\title{
Do Deutscher Hifsverein ao Colégio Farroupilha/RS: Memórias e Histórias (1858-2008)
}

BASTOS, Maria Helena Camara; JACQUES, Alice Rigoni; ALMEIDA, Dóris Bittencourt (Org.). Do Deutscher Hifsverein ao Colégio Farroupilha/RS: Memórias e Histórias (18582008). Porto Alegre: EDIPUCRS, 2013.

Karin Sewald Vieira

Mestra em Educação

Programa de Pós-Graduação em Educação

Universidade do Estado de Santa Catarina - PPGE/UDESC

ksv27@terra.com.br

\section{Para citar esta resenha:}

VIEIRA, Karin Sewald. Do Deutscher Hifsverein ao Colégio Farroupilha/RS: Memórias e Histórias (18582008). Revista Linhas. Florianópolis, v. 15, n. 28, p. 406-411, jan./jun. 2014.

DOI: $10.5965 / 1984723815282014406$

http://dx.doi.org/10.5965/1984723815282014406 
Guardado em uma “caixa embalagem" finamente ilustrada, encontra-se o livro “Do Deutscher Hilfsverein ao Colégio Farroupilha: Memórias e Histórias (1858-2008)”. Ele chega às mãos dos(as) leitores(as) envolvido delicadamente por uma fita de cetim e sua capa em tons de marrom acobreado tem o título escrito em dourado. Os tons anunciam a sofisticação da obra e, ao folhear as páginas, os detalhes saltam aos olhos e instigam o desejo de leitura; seja pela presença das letras góticas, das ilustrações de pequenas penas que indicam a numeração das páginas, seja pelas belas fotografias, gráficos e tabelas que compõem a cena do impresso. Assim, no que diz respeito à materialidade, que se substantiva nos processos de editoração, a presente obra está impecável e evidencia o uso de alta tecnologia em sua construção onde, passado e presente parecem se entrelaçar para narrar a trajetória histórica de uma importante instituição escolar do Rio Grande do Sul, o Colégio Farroupilha, proposta pelas professoras Maria Helena Camara Bastos (PUCRS), Alice Rigoni Jacques (Memorial do Colégio Farroupilha) e Dóris Bittencourt Almeida (UFRGS).

O livro é fruto da constituição do Memorial do Colégio Farroupilha, em 2002 e do Grupo de Pesquisa “Entre Memórias e Histórias da Escola do Rio Grande do Sul: do Deutscher Hilfsverein ao Colégio Farroupilha (1858-2008)", em 2008 e congrega as seguintes instituições de ensino: Pontifícia Universidade do Rio Grande do Sul (PUCRS), Universidade Federal do Rio Grande do Sul (UFRGS), FEEVALE, UNISINOS, Colégio Farroupilha. As instituições de fomento à pesquisa - Conselho Nacional de Desenvolvimento Científico e Tecnológico/CNPq e Fundação de Amparo à Pesquisa do Estado do Rio Grande do Sul/FAPERGS apoiam o projeto. A coletânea, lançada em 2013, é apresentada pelas organizadoras e prefaciada pela professora Dra. Carlota Reis Boto, do Departamento de Filosofia e Ciências da Educação e da Pós-Graduação em Educação da Universidade de São Paulo (USP).

A obra tem por objetivo refletir sobre os diferentes aspectos que compõem a instituição e igualmente analisar a(s) cultura(s) ou a(s) gramática(s) desse espaço educativo, destacando e problematizando a composição do Colégio Farroupilha, no recorte temporal que abrange sua fundação (1858) até 2008. Para tanto um elemento, o Memorial, que compõe a cultura escolar contemporânea do Colégio, parece assumir o 
protagonismo nos estudos ora apresentados. De modo geral, o arquivo do Memorial Do Deutcher Hilfsverein ao Colégio Farroupilha mobilizou os pesquisadores e pode ser tomado como um exemplo das possibilidades variadas de investigações ofertadas neste livro que se apresenta organizado na forma de capítulos onde os textos, de diferentes pesquisadores - professores, graduandos, mestrandos e doutorandos - estão dispostos de forma independente, permitindo ao leitor, eleger a ordem de leitura que desejar.

O primeiro capítulo intitulado "O Associativismo entre Alemães e Descendentes no Rio Grande do Sul”, de René Ernaini Gertz, antecede os estudos mais específicos do Colégio. O autor introduz o tema de seu artigo, questionando as concepções sobre o possível "caráter associacionista", atribuído por muitos, como inato aos imigrantes alemães e seus descendentes e amplia a questão criticando o senso comum arraigado que aponta a indiferença dos imigrantes alemães às políticas gaúcha e brasileira. Alice Rigoni Jacques, no texto "A Associação Beneficente e Educacional de 1858 e o Colégio Farroupilha (1886)" narra a história da Associação Beneficente e Educacional como instituição mantenedora do Colégio Farroupilha.

No texto, “O Memorial do Deutscher Hilfsverein ao Colégio Farroupilha: Um Espaço de Ensino e Pesquisa (2002)", os autores Alice Rigoni Jacques e Lucas Costa Grimaldi conduzem os leitores para o interior do acervo do Memorial, criado em 2002 e aqui trabalhado como ferramenta de estudos, espaço de experimentação, preservação, comunicação e de indagações. A finalidade, os espaços, o processo de cadastro, a organização e composição do acervo, o funcionamento e as doações do Memorial são descritos através de itens elucidativos dispostos em tabelas e fotografias. A arquitetura escolar é discutida por Alice Rigoni Jacques e Tatiane de Freitas Ermel, no texto "O Velho Casarão: um estudo sobre o Knabensechule des Deutsches Hilfsverein/ Colégio Farroupilha (1895-1962)". A construção do prédio e os primeiros anos de funcionamento, seus diferentes espaços, a inspeção do ensino e os objetos escolares que compõe a Instituição, são investigados por meio de documentos tais como, a planta do funcionamento do prédio, fotografias e relatórios do Ministério e de Inspeção de Ensino.

O texto seguinte, escrito por Milene Moraes de Figueiredo, recebe o título "O Kindergarten do Deutscher Hilfsverein (1911-1929)". A autora, analisando Relatórios Anuais 
e Atas da Associação Beneficente Alemã, entrevistas e fotografias, apresenta o pioneirismo do Jardim de Infância da Associação, na cidade de Porto Alegre. O texto permite reflexões acerca da concepção de infância daquele tempo associada ao Sistema Fröebel e ao Método Intuitivo. O texto seguinte, intitulado "A Imprensa Escolar do Colégio Alemão: Das Band e Relatório Mensal do Ginásio Teuto-Brasileiro Farroupilha (1929-1939)", escrito por Lucas Costa Grimaldi e Dóris Bittencourt Almeida, analisa dois periódicos editados por alunos e professores. O jornal Das Band editado entre 1929 e 1938 e o Relatório Mensal do Ginásio Teuto-Brasileiro Farroupilha, de 1939, são tomados como documentos para analisar a imprensa escolar e oferecem pistas para a compreensão das mudanças que a escola atravessou durante o Estado Novo.

A história de vida da professora alfabetizadora Lia Mostardeiro é o tema do estudo de Dóris Bittencourt Almeida, intitulado "Um Caminho de Pregnâncias: Os Cinquenta Anos de Alfabetização da Professora Lia Mostardeiro (1945-1994)". A memória foi problematizada como documento e a metodologia utilizada para o estudo foi a História Oral. Assim o corpo documental deste artigo constitui-se em entrevistas realizadas com a professora foco desse estudo. Em “Memórias Juvenis nas Páginas de um Periódico: 0 Clarim (1945-1965)", Dóris Bittencourt Almeida e Valeska Alessandra de Lima, elegem a revista O Clarim, do Grêmio Estudantil do Colégio Farroupilha, para discutir e analisar os discursos que emergem sobre a cultura juvenil dessa instituição. No texto seguinte, “Cartilha, Festa e Escrita Infantil: Álbuns e Cartas dos Alunos do Curso Primário (19481966)" as escritas escolares são analisadas, por meio de álbuns confeccionados pelas professoras do primeiro ano e a escrita epistolar dos alunos, pelas pesquisadoras Maria Helena Camara Bastos e Alice Rigoni Jacques.

Alice Rigoni Jacques, em “Do Carimbo à Caneta Vermelha: Marcas de Correção em Cadernos Escolares (1948/1958)", mobiliza os cadernos escolares, com o objetivo de problematizar as marcas de correção. Para a autora, tais marcas são pensadas como práticas discursivas reveladoras das relações de ensino e de aprendizagem, no Curso Primário do Colégio Farroupilha. Álbuns e fotografias, logotipo, flâmula, convite de formatura, livros de atas e relatórios compõem o corpus documental do estudo, organizado por Pietro Gabriel dos Santos Pacheco, intitulado "A Escola Técnica de 
Comércio Farroupilha (ETC/1949-1982)”. O estudo apresentou parte do itinerário histórico da Escola Técnica responsável pela formação de profissionais nas áreas de comércio e contabilidade na cidade de Porto Alegre.

Em “Meu Diário: Escritas de Si na Escola Primária (1951-1957)”, Maria Helena Camara Bastos analisa cadernos utilizados no Curso Primário, entre eles os chamados Meu diário e cadernos de redação, pensados na clave de escritas autobiográficas e escritas de si e, também, como "escritas obrigatórias". No texto seguinte "Um Retrato Multicolorido da Escola: Cadernos de uma Aluna Singular (1953-1957)", produzido pela mesma autora, o acervo pessoal - cadernos organizados na forma de tomos - de uma professora, que foi aluna do Colégio Farroupilha é objeto de estudo. Os cadernos são analisados desde a sua materialidade, passando pelos processos de didatização do ensino, as disciplinas escolares, os exercícios e os critérios de avaliação.

O uniforme escolar é o tema da produção dos pesquisadores Raphael Castanheira Scholl e Alice Rigoni Jacques. Em “À Moda da Escola: O Uniforme Feminino (1950)" o acervo fotográfico é escolhido como documento para mobilizar o estudo sócio-histórico do uniforme escolar e suas relações como movimento da moda. No texto que segue, "A Lembrança em Preto e Branco: Imagens de Primeira Comunhão (1958-1969)", de autoria de Raphael Castanheira Scholl e Lucas Costa Grimaldi, a coleção de fotografias do Memorial é novamente movimentada. No entanto, a análise centrou-se em uma série de fotografias específicas, e teve como objetivo compreender o ritual da primeira comunhão - seus significados religiosos e pedagógicos - como parte da cultura escolar do Colégio Farroupilha. Por fim, no capítulo "Territórios de Professoras: O Currículo e as Práticas Escolares nos Registros da Matéria", Luciana Sgarbi Grazziotin por meio dos Cadernos de Classe, também chamados de Diários de Professoras ou Registro de matérias procurou entender a instituição educativa em sua multidimensionalidade. A autora, ancorada em Foucault, tomou os Cadernos de Classe como territórios de professoras, ou seja, como espaços determinados por diferentes tipos de poder - da mantenedora, dos gestores, das famílias e também dos próprios pares.

Ao longo da obra, a história do Colégio Farroupilha está transversalizada com a história do estado do Rio Grande do Sul demonstrando assim, a importância das relações 
conjuntas entre a instituição escolar e o lugar onde se situa. Os diferentes aspectos que compuseram e compõe a cultura escolar desta instituição de ensino são detalhados pelos pesquisadores em seus estudos e o protagonismo do Memorial Do Deutscher Hilfsverein ao Colégio Farroupilha atravessa o conjunto da obra, notadamente pela sua política da constituição de acervos, salvaguarda e preservação de seus materiais imprescindíveis à pesquisa histórica.

Em um tempo de fascínio pela memória e de culto ao patrimônio (HUYSSEN, 2000) este livro, pela pesquisa criteriosa nos arquivos, pela escrita envolvente e pela atualidade da temática, já nasce como uma leitura fundamental, pois, observa-se, em todos os seus textos, a importância do arquivo para a construção de um memorável trabalho historiográfico, ainda que seus autores tenham evitado contar mais detalhadamente as tensões, disputas e conflitos que, certamente, envolveram a construção de um trabalho deste quilate. O presente demandando o passado - é o que fizeram e fazem os pesquisadores que empreenderam esta obra. Nada mais atual e necessário.

Boa leitura a todos(as).

\section{Referência}

HUYSSEN, Andreas. Seduzidos pela memória: arquitetura, monumentos, mídia. Rio de Janeiro: Aeroplano, 2000.

Recebido em: 20/03/2014 Aprovado em: 01/05/2014

Universidade do Estado de Santa Catarina - UDESC Programa de Pós-Graduação em Educação - PPGE Revista Linhas

Volume 14 - Número 28 - Ano 2014 revistalinhas@gmail.com 